This item was submitted to Loughborough's Research Repository by the author.

Items in Figshare are protected by copyright, with all rights reserved, unless otherwise indicated.

\title{
Smart meter data: balancing consumer privacy concerns with legitimate applications
}

PLEASE CITE THE PUBLISHED VERSION

http://www.journals.elsevier.com/energy-policy/

PUBLISHER

(C) Elsevier Ltd.

VERSION

AM (Accepted Manuscript)

LICENCE

CC BY-NC-ND 4.0

REPOSITORY RECORD

McKenna, Eoghan, lan Richardson, and Murray Thomson. 2019. "Smart Meter Data: Balancing Consumer Privacy Concerns with Legitimate Applications”. figshare. https://hdl.handle.net/2134/9248. 
This item was submitted to Loughborough's Institutional Repository (https://dspace.lboro.ac.uk/) by the author and is made available under the following Creative Commons Licence conditions.

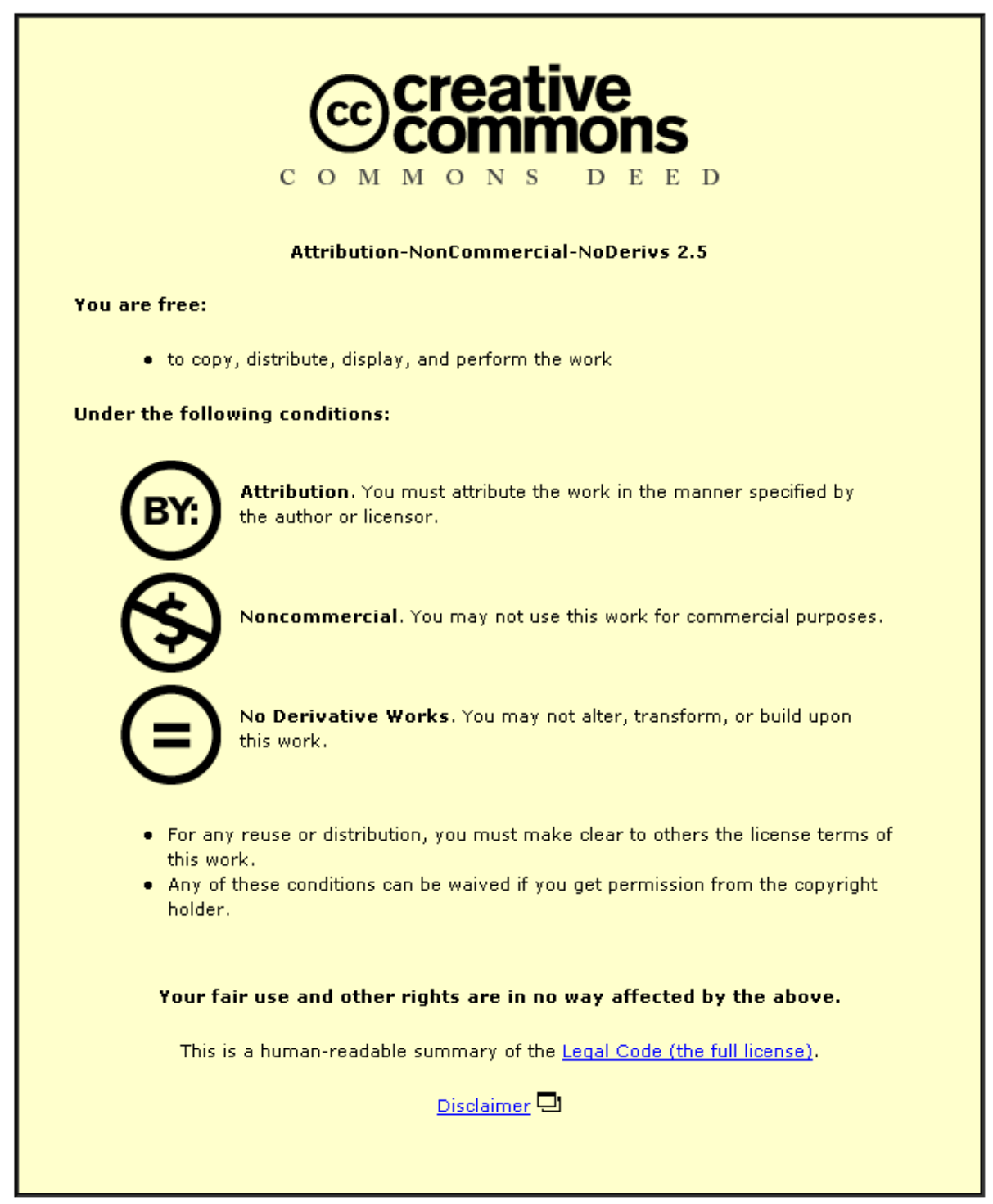

For the full text of this licence, please go to: http://creativecommons.org/licenses/by-nc-nd/2.5/ 


\title{
Smart meter data: Balancing consumer privacy concerns with legitimate applications
}

\author{
Eoghan McKenna*, Ian Richardson and Murray Thomson \\ CREST (Centre for Renewable Energy Systems Technology), \\ School of Electronic, Electrical and Systems Engineering, \\ Loughborough University, Leicestershire, LE11 3TU, UK \\ *Corresponding author: E.J.McKenna@lboro.ac.uk, +44 7958531842.
}

Keywords: smart meter, consumer privacy, data protection. 


\begin{abstract}
:
Smart meters are being rolled out in large numbers throughout the world, with proponents claiming they are a critical step in the transition to a lowcarbon economy. Yet there are significant unresolved negative reactions to smart meters, principally based on the concern that smart meters might be used to infer the private activities that occur within a dwelling. Though smart meter data is classified as personal data, and as such protected under existing data protection frameworks in the EU, there are relevant exceptions, notably where the data is required for legitimate applications associated with the performance of 'regulated duties'. This paper contributes to this debate by examining the data requirements for some of the proposed applications of smart meter data within the electricity supply industry, and investigates whether the use of personal data can be minimised or even avoided. The discussion includes system balancing, demand reduction, demand response and distribution network operation and planning, and indicates that, for most of these applications, the requirements for personal data can indeed be minimised. 'Privacy friendly' alternatives are discussed.
\end{abstract}




\section{Drivers for growth and risks of rejection}

Smart meters are being installed in large numbers throughout the world due to the benefits they are expected to bring to the electricity supply industry and its customers. Different stakeholders have different objectives: suppliers (the companies that purchase electricity in the wholesale market and sell electricity to consumers in the retail market) are expecting to reduce operational overheads associated with manual meter reading and potentially improve customer loyalty or 'stickyness' (Rogai, 2006); the operators of the transmission system and distribution networks hope to benefit from a more flexible demand side to enable greater penetrations of low-carbon technologies (Strbac et al., 2010); governments hope that the improvements in end-use energy efficiency promised by smart meters will help to achieve binding carbon reduction targets (Department for Energy and Climate Change, 2010); and end-users may hope to benefit from reduced electricity bills as they become more energy aware (Darby, 2006; Mott MacDonald, 2007; Owen and Ward, 2006). With such expectations, it is no surprise that smart meters are undergoing a period of rapid growth (IDC Energy Insights, 2011). 
There are however significant unresolved negative reactions to smart meters. Some journalists have accused smart meters of having the potential to be a 'spy in the home', which will allow governments to monitor household behaviour (Jamieson, 2009). In Germany, the electricity supplier Yello Strom GmbH 'won' an award in the Technology category of a 'Big Brother' awards ceremony in 2008 for its plans to introduce smart meters to its customers. The judges of the yearly event, which is organised by the 'FoeBuD' civil rights and privacy campaign group, thought that the supplier's smart metering activities would 'potentially lead [...] to a detailed surveillance of activities in the home' (FoeBuD e.V., 2008). Perhaps of most significance for EU member states, in April 2009, the Dutch Senate rejected a Smart Metering Bill, which would have mandated the installation of smart meters in every home in Holland (TILT, 2009). The Senate argued that the bill violated a citizen's right to privacy under European law. As a result, smart meters are now being rolled-out on a voluntary basis in Holland, considerably reducing their rate of deployment. Such negative reactions evidently have the potential to hinder the uptake and acceptance of smart meters throughout the world. 
Perhaps the most obvious concern is that commercial entities, including companies of various forms, will seek to use smart meter data as a means to gather information about their market and customers. Less obvious perhaps, and certainly less discussed, is that smart meters may have consequences for the internal privacy of households. Imagine for example a domineering father using smart meter data to check up on the behaviours of his children or other family members. It is one thing to try to fend off a persistent marketing company that is trying to sell you something, but quite another thing if the person analysing your activities is someone you know personally.

Thus we see that what started out as a purely technical and commercial ambition has evolved into a complex debate of privacy and ethics. The installation of smart meters is presented by their proponents as a critical step in the transition to a low-carbon economy, yet it is a step that could prove unwelcome to consumers if their privacy concerns are not adequately considered. The following sections of this paper first explore the concerns in more detail and then look at the legal framework for data protection. Following this, the various anticipated uses of smart meter data are discussed.

\section{What are the privacy concerns, and are they valid?}

\subsection{Summary of concerns}

The main privacy concerns related to smart meters that have been reported in the literature have been summarised in Table 1 and have been grouped according to the type of application for which the data could be used. 
Table 1 - Summary of privacy concerns related to smart meters.

\begin{tabular}{|c|c|c|}
\hline $\begin{array}{l}\text { Application } \\
\text { group }\end{array}$ & Example concerns & References \\
\hline Illegal uses & $\begin{array}{l}\text { Burglars finding out when homes are } \\
\text { unoccupied. } \\
\text { Stalkers tracking the movements of } \\
\text { their victims. }\end{array}$ & $\begin{array}{l}\text { (Lisovich et al., } \\
\text { 2010; Quinn, 2009; } \\
\text { Cavoukian et al., } \\
\text { 2010; McDaniel, } \\
\text { 2009; Lerner and } \\
\text { Mulligan, 2008; } \\
\text { Subrahmanyam, } \\
\text { 2005) }\end{array}$ \\
\hline $\begin{array}{l}\text { Commercial } \\
\text { uses }\end{array}$ & $\begin{array}{l}\text { Targeted advertising: Use of individual } \\
\text { or aggregated household smart meter } \\
\text { data to target advertising at a specific } \\
\text { household or individual. Note: use of } \\
\text { aggregated or 'anonymous' data may } \\
\text { be more acceptable than use of } \\
\text { individual household data. } \\
\text { Insurance adjusting e.g. do you tend to } \\
\text { leave your appliances on when away } \\
\text { from home? }\end{array}$ & $\begin{array}{l}\text { (Lisovich et al., } \\
\text { 2010; Quinn, 2009; } \\
\text { Cavoukian et al., } \\
\text { 2010; McDaniel, } \\
\text { 2009; Anderson } \\
\text { and Fuloria, 2010; } \\
\text { Bohli et al., 2010) }\end{array}$ \\
\hline
\end{tabular}




\begin{tabular}{|c|c|c|}
\hline $\begin{array}{l}\text { Uses by law } \\
\text { enforcement } \\
\text { agencies }\end{array}$ & $\begin{array}{l}\text { Detection of illegal activities e.g. } \\
\text { sweatshops, unlicensed commercial } \\
\text { activities, drug production. } \\
\text { Verifying defendant's claims e.g. that } \\
\text { they were 'at home all evening'. }\end{array}$ & $\begin{array}{l}\text { (Lisovich et al., } \\
\text { 2010) }\end{array}$ \\
\hline $\begin{array}{l}\text { Uses by } \\
\text { other parties } \\
\text { for legal } \\
\text { purposes }\end{array}$ & $\begin{array}{l}\text { In a custody battle: do you leave your } \\
\text { child home alone? } \\
\text { In a landlord-tenant dispute: is the } \\
\text { property over-occupied? }\end{array}$ & (Quinn, 2009) \\
\hline $\begin{array}{l}\text { Use by family } \\
\text { members and } \\
\text { other co- } \\
\text { inhabitants }\end{array}$ & $\begin{array}{l}\text { One householder 'spying' on another } \\
\text { e.g. parents checking if their children } \\
\text { are sleeping or staying up late playing } \\
\text { video games. } \\
\text { Partners investigating each other's } \\
\text { behaviour. }\end{array}$ & $\begin{array}{l}\text { (Hargreaves et al., } \\
2010)\end{array}$ \\
\hline
\end{tabular}




\subsection{Data resolution determines information disclosure}

All of the concerns listed above are based on a single concept: that smart meters might be used to reveal certain activities that occur within a dwelling - activities that people generally expect to be private. The ability to detect specific activities however depends on the time resolution of the consumption data. For example, quarterly or monthly readings of cumulative energy consumption are unlikely to reveal anything more than the dwelling's mean energy use and an indication of whether or not it was occupied - a long holiday for example could likely be identified. As the reading intervals are reduced however, more information can be ascertained. Daily recorded data for example could reveal that residents went away for the weekend or even that they go away every weekend. As the data interval is further reduced, a 'load profile' is revealed, and this can then be used to observe the characteristic power consumption patterns associated with the usage of individual appliances and other domestic loads.

To illustrate this point, an individual dwelling's load profile at different levels of resolution is shown in Figure 1. The half-hourly data shown in the top graph provides a good indication of active occupancy throughout the day we use 'active' to mean not asleep. In this case, it appears that people got up around 6am and likely went out. They returned around 9:30 and were busy until 18:30. They may then have gone out for the evening, and returned around 23:00. Clearly there is a degree of speculation in this analysis, but with a little practice it is perfectly possible to identify the general movements of residents with some confidence from half-hourly data. 

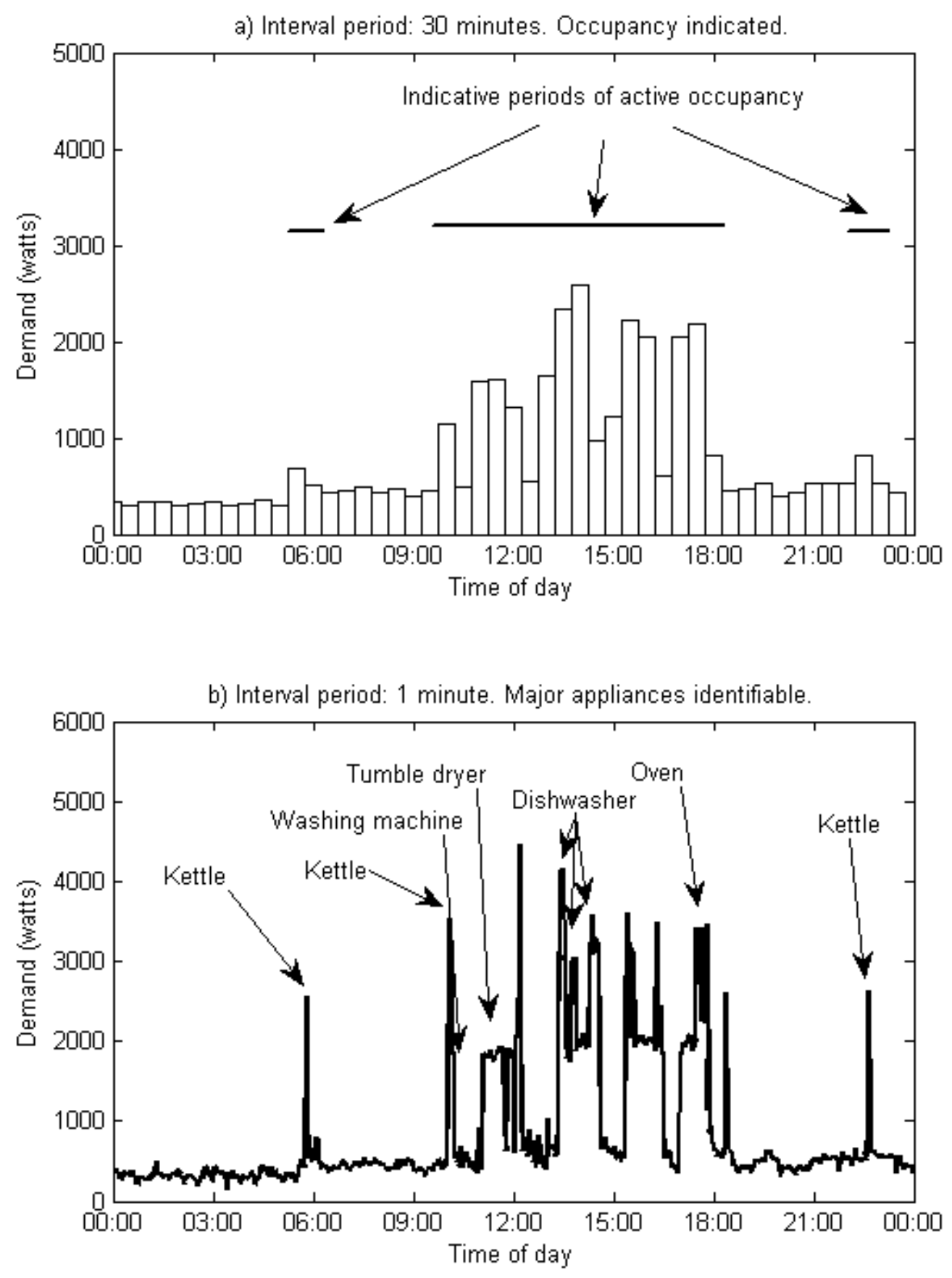

Figure 1 - Demand data for a single dwelling averaged over half-hour and 1 minute intervals. Source: DEHEMS (2011). 
The lower graph uses 1-minute data (a resolution that some smart meters are already capable of) and illustrates the much greater detail that can be inferred. The annotations of specific appliances on this graph are actually known from additional data (in the form of appliance level plug monitors) that is not shown here. The point of the illustration however, is that a trained eye can identify the use of major appliances, based on their characteristic patterns of demand. A washing machine, for example, is typically characterised by a spike at the beginning of the cycle, associated with heating the water, and a second smaller spike at the end, associated with the spin. Performance of such analysis by-eye is relevant in the discussion of one householder checking up on another. More generally, such analysis can be performed by computers to provide extensive details of appliance use over long periods of time. Indeed this type of analysis is already a well developed technique, particularly for the purpose of Non-Intrusive Load Monitoring (NILM) (Drenker and Kader, 1999). Further reduction of the metering interval, for example to 1-second, greatly increases the range of identifiable appliances.

Figure 2 summarises the type of information that can be inferred from data of increasing resolution. Most smart meters currently being installed worldwide log data hourly, half-hourly or at 15-minute intervals. This can provide a strong indication of occupancy, but has much less potential to reveal individual appliance use. Future generations of smart meters may be configured to provide much higher resolution. Concerns should be rationalised accordingly. 


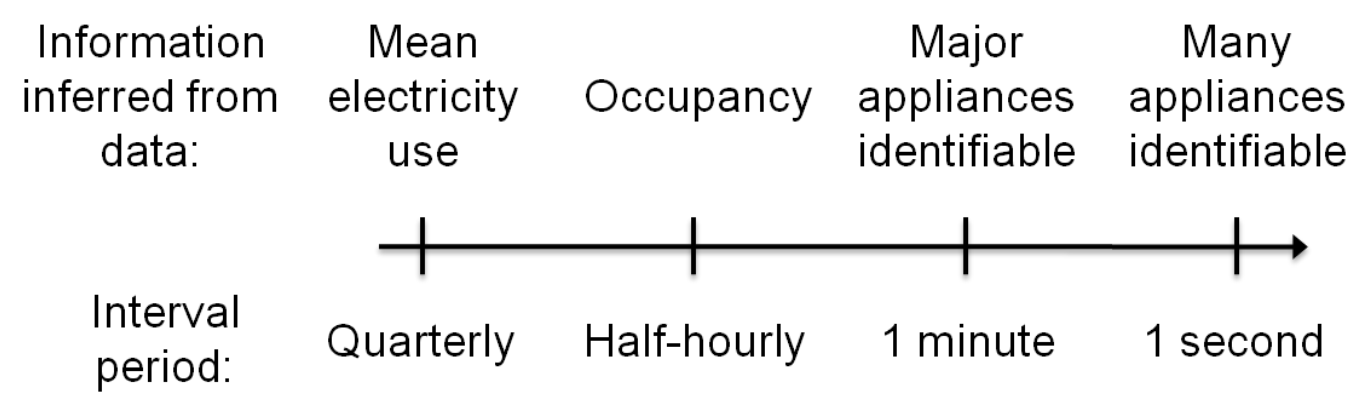

Figure 2 - Examples of information that can be inferred from increasing meter data resolution.

Smart meter data is therefore justifiably viewed as being potentially sensitive personal data. The next section examines whether the data protection framework in the EU provides protection for consumers regarding the use of this data. 


\section{The legal framework: are consumers protected?}

Article 8 of the European Convention on Human Rights provides every EU citizen with 'the right to respect for his private and family life, his home and his correspondence', and that there shall be no interference by a public authority with the exercise of this right except where it is in the 'interests of national security, public safety or economic well-being of a country' (Council of Europe, 1950). Indeed the Dutch Senate voted against plans for a mandatory roll-out of smart meters because it was argued that the plans violated the European Convention on Human Rights. This was based on the following grounds (Engage Consulting, 2010): that consumers should have the right to refuse the installation of the smart meter; that the planned 15minute load profile data recorded by the meters could reveal personal data; that the data storage was vulnerable; and that the ability for the utility to disconnect consumer remotely constituted a restriction of a primary necessity of life (although the discussion of this last topic is beyond the scope of this paper). 
This fundamental right to privacy has been interpreted as a right to data protection for EU citizens, which has been established within the EU Data Protection Directive (CEC, 1995). The Data Protection Directive sets out common binding rules for data protection that each member state must adhere to by implementing national legislation that is consistent with the Directive's standards. Load profile data that allowed the identification of an individual, whether from the data itself or from the data and other held information such as a name and address, would be classified as personal data according to the Directive, and so should fall under its protection. In particular, according to the Directive, personal data should be collected only for specified purposes, that data should be adequate and not excessive, and it should be kept in a form allowing identification for no longer than strictly necessary.

In addition to these principles, personal data may only be legitimately processed according to the conditions specified in Article 7 of the Directive. These have been listed below in order of their applicability to smart metering according to Knyrim and Trieb (2011):

a) processing is necessary for compliance with a legal obligation to which the controller is subject; or

b) processing is necessary for the performance of a contract to which the data subject is party or in order to take steps at the request of the data subject prior to entering into a contract; or

c) the data subject has unambiguously given his consent; or 
d) processing is necessary for the purposes of the legitimate interests pursued by the controller or by the third party or parties to whom the data are disclosed, except where such interests are overridden by the interests for fundamental rights and freedoms of the data subject which require protection under Article 1 (1) [of the Data Protection Directive]

Knyrim and Trieb (2011) argue that the most favourable legal basis for smart meters would consist of a comprehensive national or European legal obligation that allowed the data controller to collect and process personal data. This could be justified under Article 13 of the Directive, which lists relevant exemptions and restrictions. Accordingly, Member States can restrict the scope of the obligations of the Data Protection Directive, where such restrictions are necessary to safeguard:

(a) national security;

(b) defence;

(c) public security;

(d) the prevention, investigation, detection and prosecution of criminal offences, or of breaches of ethics for regulated professions;

(e) an important economic or financial interest of a Member State or of the European Union, including monetary, budgetary and taxation matters;

(f) a monitoring, inspection or regulatory function connected, even occasionally, with the exercise of official authority in cases referred to in (c), (d) and (e); 
(g) the protection of the data subject or of the rights and freedoms of others.

These exceptions could prove to be highly relevant for smart meter data. For example, meter data has long been used for detecting and prosecuting criminals - perhaps the most obvious being the detection of electricity theft (Depuru et al., 2011). Furthermore, as shall be discussed in the following section, smart meter data has relevant applications associated with regulated duties in the management of the electricity supply system. Indeed, Ofgem and DECC, who have been managing the policy design phase of the smart meter implementation programme in the UK, concluded that 'consumers will have a choice over how their consumption data is used and by whom, except where data is required to fulfil regulated duties' (Ofgem and DECC, 2011). Work is therefore underway to explicitly define regulated duties, though the Government has been 'minded to define regulated duties narrowly' (Ofgem and DECC, 2011).

Nonetheless, regardless of the most appropriate legal basis for the processing of smart meter data, and however regulated duties are defined, the principles of the Data Protection Directive should still be adhered to, and personal data should only be processed where it is necessary and relevant for the purposes of the legitimate application. The next section therefore examines the data requirements of some of the proposed applications, and in particular, questions whether the use of personal data in these applications can be minimised or even avoided. 


\section{Applications for smart meter data: can the use of personal data be minimised or avoided?}

\subsection{System balancing and transmission network power flows}

System balancing, to maintain frequency, and the management of transmission network power flows, to maintain secure operation of the whole power system, require an accurate view of demand at large substations (grid/bulk supply points) in real time and forecasted into the future. The realtime demands at these large substations are conventionally metered to provide this instantaneous view. There is no obvious role for domestic smart meter data in this real-time domain. 
The forecasting of national and regional demands is also conventionally based on this high-level substation metered data. 'Top-down' analysis of the logged data provides accurate predictions of aggregated demands with respect to time-of-day, day-of-week, weather, television schedules etc. There may be potential to enhance these demand forecasts through the addition of 'bottom-up' analysis based on data from domestic smart meters; see Swan and Ugursal (2009) for discussion of top-down and bottom-up techniques. One such enhancement could be an improved quantification of embedded generation, which is unavoidably mixed with demand in conventional substation metering. A second could be improved prediction of demand under unusual conditions, such as a major frequency disturbance or low voltage conditions. Smart meter data from individual dwellings could be used in this bottom-up analysis, but it is anticipated that volunteered and anonymised data from a subset of dwellings would be entirely adequate for this. 
The above discussion refers mainly to the System Operator (National Grid in the case of the UK), in their performance of a 'regulated duty'. Suppliers also need accurate demand forecasts, in order to estimate the anticipated demand of their consumers, and to trade for these volumes in the wholesale electricity market. As profit-making private companies, suppliers are not performing a regulated duty in this regard - and thus have no claim to smart meter data in this way. As a result, it is most likely that suppliers, seeing a value in the potential for smart meter data to improve their demand forecasts, would need to obtain explicit consent from their consumers allowing their data to be used in this way. Nonetheless, it is arguable that it is very much in the public interest that suppliers do achieve a good balance, as this would minimise the costs incurred by the System Operator in resolving any system imbalances. Achieving a good supplier balance would therefore contribute to the overall efficiency of the system.

It would appear therefore that system balancing is a legitimate application for smart meter data, though one that need have little or no impact in terms of consumer privacy. 


\subsection{Demand reduction}

Smart meter data can be used for demand reduction applications, specifically by providing improved information feedback to domestic consumers about their consumption. The EU Electricity Directive (CEC, 2009), which stipulates that Member States shall equip $80 \%$ of their consumers with 'intelligent metering systems' (where cost-effective) by 2020, explicitly requires that consumers have 'at their disposal' their consumption data at no extra cost, and that they 'are properly informed of actual electricity consumption and costs frequently enough to enable them to regulate their own energy consumption'.

Smart meters can improve feedback of energy consumption in two ways: local feedback, for example through an in-home display unit that communicates directly with the meter, or remote feedback, such as 'informative billing' (Darby, 2006) or on-line via the internet. This on-line feedback could be provided by the supplier, or indeed any other party providing an energy efficiency service to the consumer. See Darby (2006; 2000) for discussion on the effectiveness of feedback on energy consumption.

With local feedback, data is kept within the home and any data processing is typically performed in the meter itself or in the in-home display unit. This is the expected architecture for the UK smart meter roll-out (Ofgem and DECC, 2011), and has some merits from a privacy perspective, although concerns regarding internal household privacy may remain. 
Remote feedback, whereby the data leaves the home, can facilitate more sophisticated data analysis, more flexible presentation of information to consumers, and thus potentially a greater reduction of demand. This type of feedback is similar to that already being provided by third party 'clip-on' energy monitoring systems such as AlertMe (AlertMe, 2011) which is popular with some types of consumers. In these cases however, the household (or at least one member) is volunteering the data and is doing so not to the utility but to a relatively independent party. Collecting similar data directly from the utility smart meter is technically more elegant and usually more accurate but may be a rather different proposition to the householder in terms of where the data goes. Furthermore, it is likely that some consumers will welcome, use, and benefit from remote feedback, while others may perceive it as interference in their private lives.

Finally, it should be noted that some forms of remote feedback do not require high resolution data, and may thus avoid privacy concerns. A company called OPOWER for example has achieved persistent energy reductions between 1 and $3 \%$ simply by providing consumers with a comparison of their monthly consumption against that of their neighbours (Allcott, 2010). Initiatives such as this have been motivated by insights into consumer behaviour from behavioural science, and would seem to be a useful area for further research (Allcott and Mullainathan, 2010). 


\subsubsection{Feedback and privacy within the home}

In the debates surrounding privacy and smart meters, the consumer is often assumed to be a single individual, or at least a cohesive group that can reasonably be thought of as a single 'unit'. Clearly though, there are situations where this might not be the case, and where individuals within the group will want to protect their privacy from other members of the group. Lodgers or tenants that live under the same roofs as their landlords are perhaps an obvious example. Adolescents may also not welcome the additional information about their activities that smart meters might provide to their parents - imagine parents coming home from a weekend away and to teenagers that swear they did not use the house for parties - yet why was so much electricity consumed late at night?

Given that privacy is a fundamental right of the individual, individuals should be able to protect this even from other members of a shared household. Referring back to previous sections however, the main information disclosure from current (half-hourly) smart metering systems is regarding occupancy, and it is arguable that this type of information disclosure is implicitly accepted when sharing a household with others. Smart meters therefore only extend a type of information disclosure that was already present within the household, rather than introducing a new one that was not there previously. Nonetheless, smart meters do have the potential to affect household dynamics in unexpected ways, and as such it is a subject that deserves more attention. For further discussion, see Hargreaves et al. (2010) about the effects of feedback on household dynamics. 


\subsection{Demand Response}

Demand response - the ability to time-shift demand - will become increasingly valuable in the transition to a low-carbon power system (McKenna et al., 2011), and smart meters are regarded as a key enabling technology in the development of this service. Indeed, the Electricity Directive (CEC, 2009) specifically states that Member States shall implement 'intelligent metering systems that shall assist the active participation of consumers in the electricity supply market'.

Demand response is based principally on offering economic incentives, such as a dynamic pricing tariff, to the consumer, and it is critical therefore that any efforts that consumers make to change their consumption are rewarded accordingly. As demand response is time-critical, i.e. a response during a certain period can be worth more or less than a response during another period, it is necessary to be able to account for this accurately in both the retail and wholesale markets. The following sections examine the smart meter data requirements for these applications. For a broader summary of demand response in electricity markets see Albadi (2008). 


\subsubsection{Retail billing}

Given a time-varying demand and a time-varying price of electricity, retail billing can be performed in at least four different ways, as illustrated in Figure 3. Where prices vary in time in a predictable or fixed format (e.g. Economy 7 in the UK), then billing can be performed using meter registers (measurements of cumulative energy consumption), and a time clock that switches the meter from measuring on one register to another (Figure $3 \mathrm{a}$ ). The cumulative energy readings on each register can then be multiplied by the relevant price of electricity that was in effect during that register's switching period, in order to produce the consumer's bill.

a) Billing with fixed time-switched registers

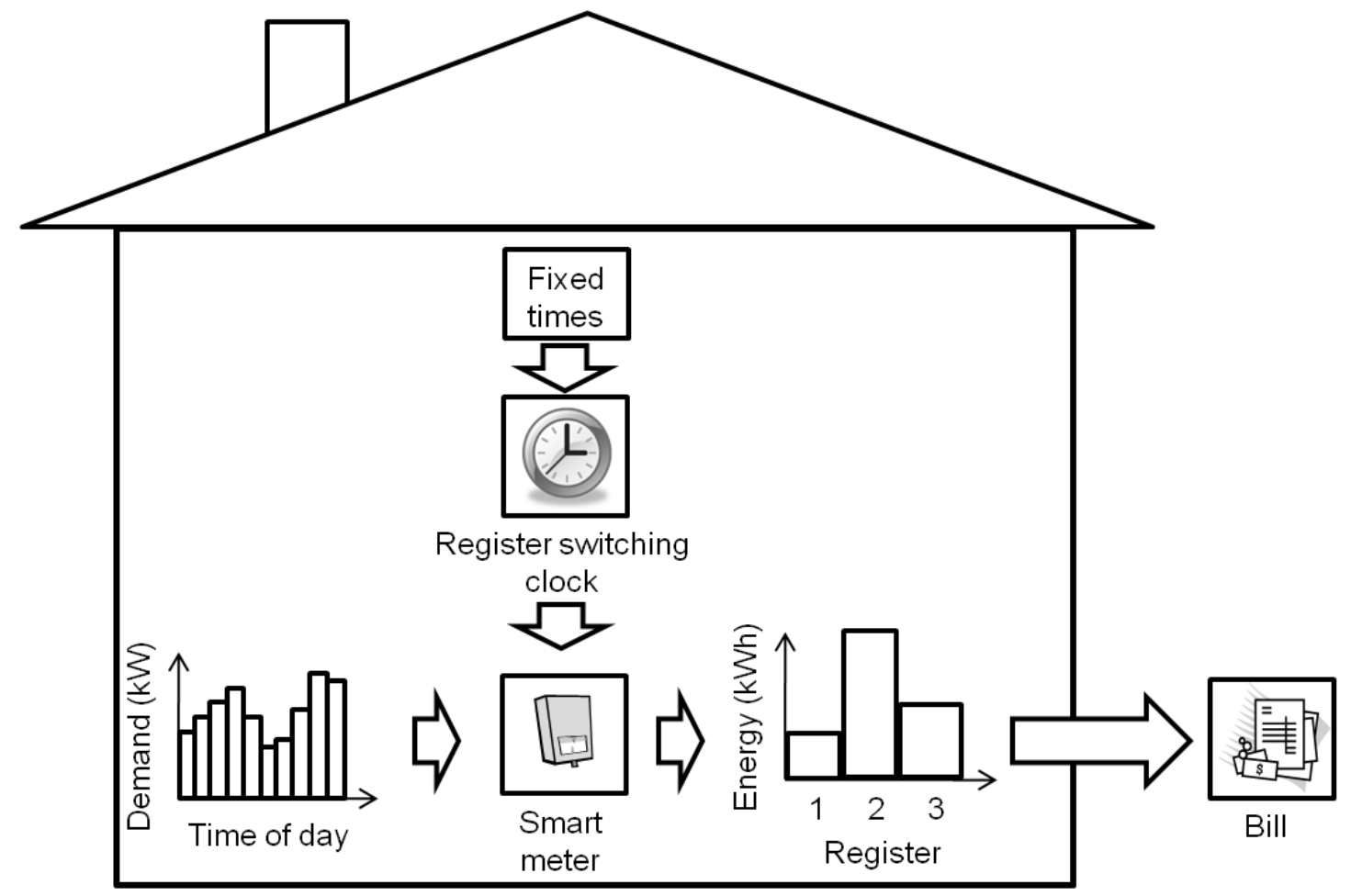


b) Billing with half-hourly interval data

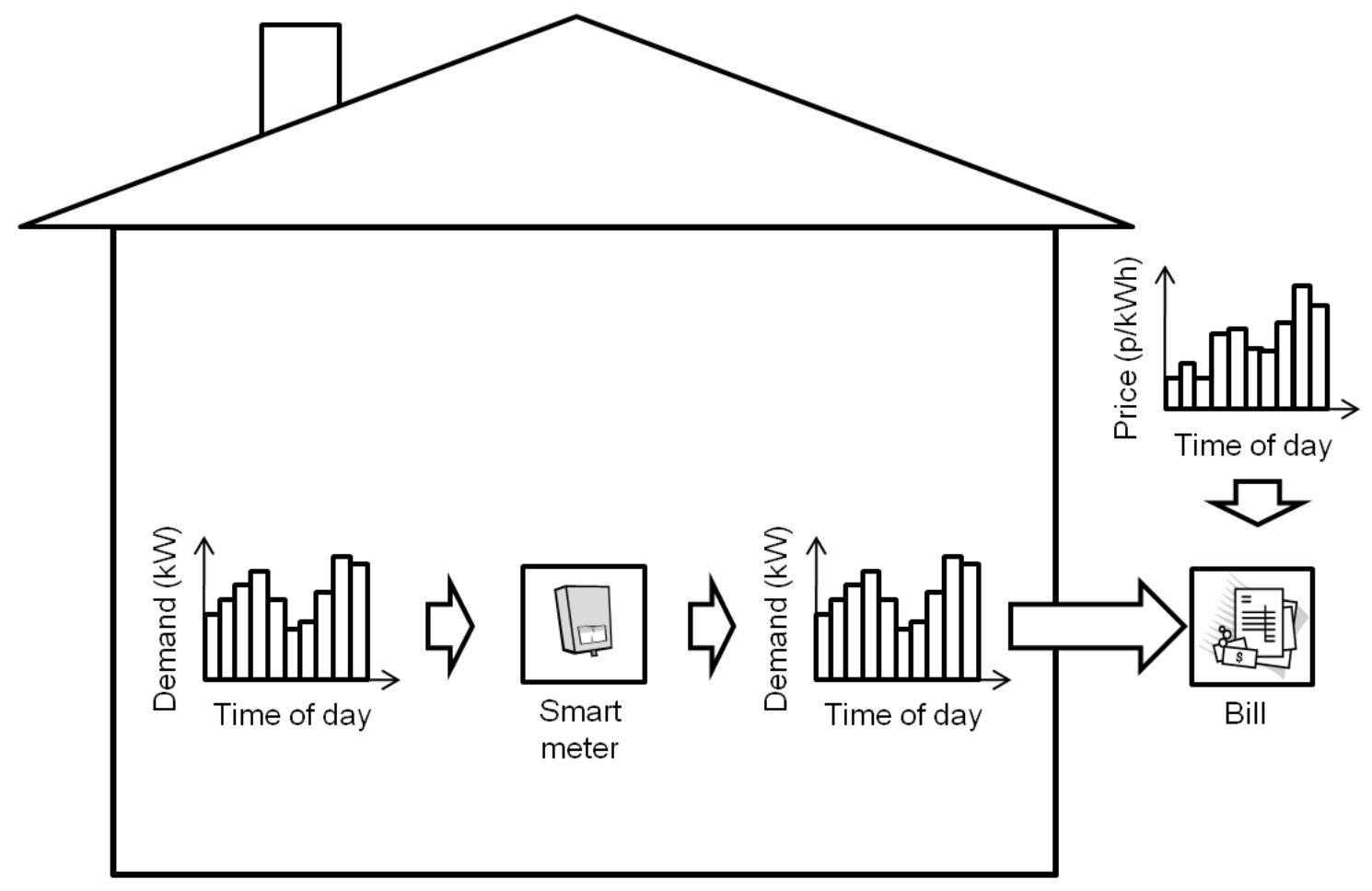

c) Billing performed by the smart meter itself

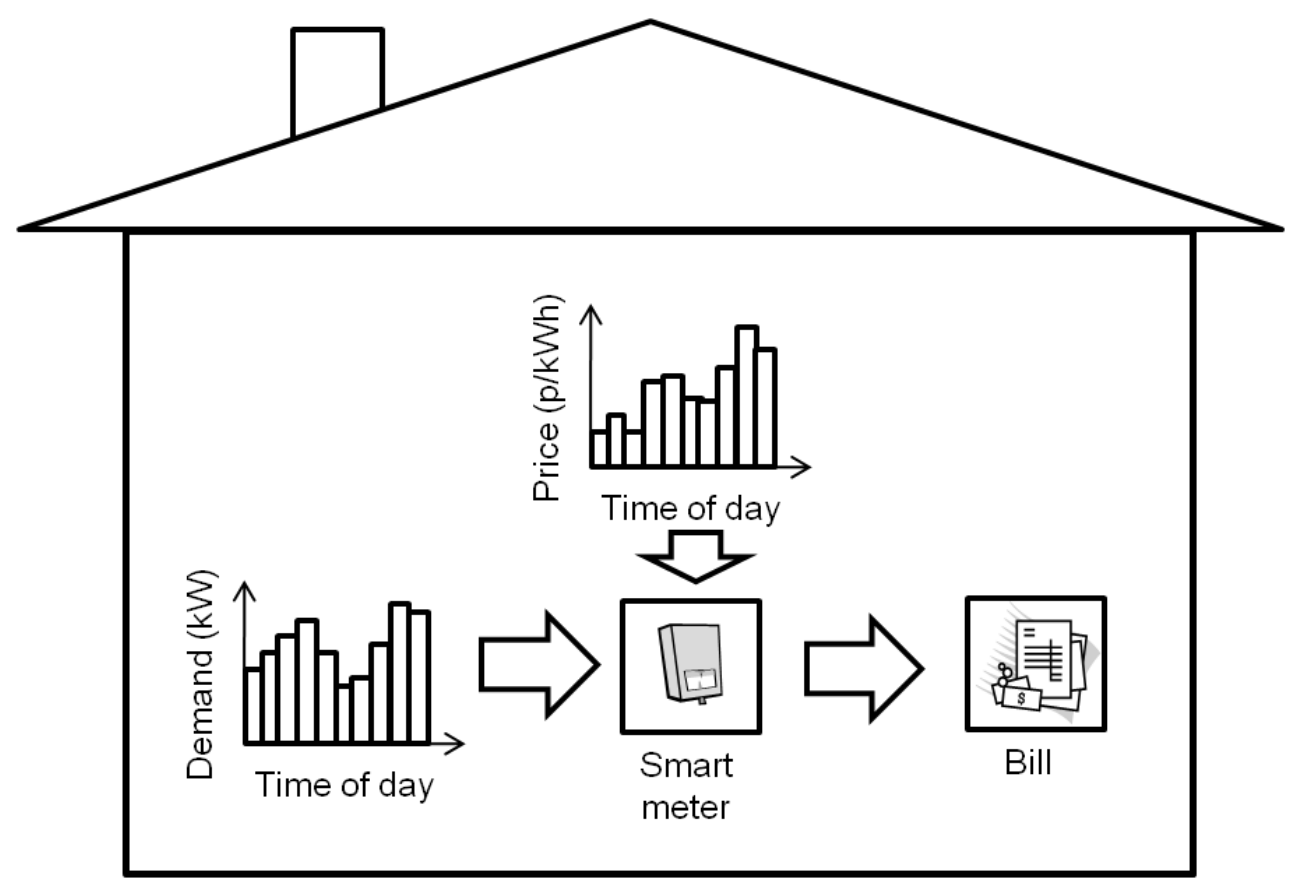


d) Billing with flexibly time-switched registers

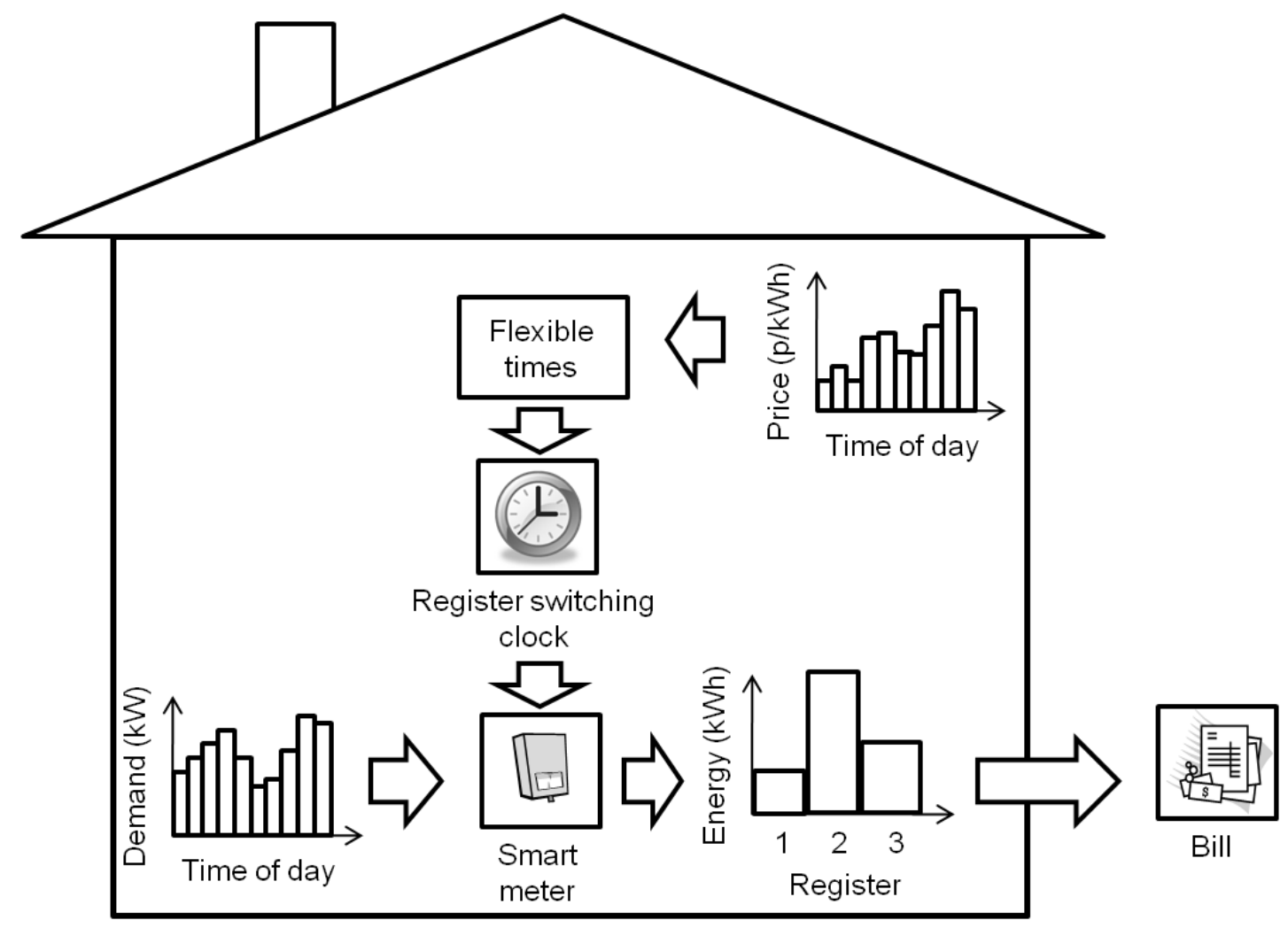

Figure 3 - Retail billing with dynamic pricing

Where prices are less predictable, billing can be performed by sending the interval data recorded by the meter to the external party responsible for billing (Figure $3 \mathrm{~b}$ ). The external party will then calculate the bill using pricing information. Large industrial consumers on dynamic pricing contracts are traditionally billed in this manner.

A third option is that prices are sent to the smart meter, which then calculates the bill itself (Figure $3 \mathrm{c}$ ). This price information could be broadcast to many meters at once, thus minimising communications bandwidth requirements. Furthermore, it need not be communicated in real-time: a smart meter could perfectly well log the high-resolution consumption data locally until it received a batch of pricing data with which to perform the calculation. 
Finally, in Figure $3 \mathrm{~d}$, rather than sending price information to the meter, it is the switching times of the meter registers that are adjusted dynamically. They can be adjusted from day to day or on short notice if required.

Notice that only option b out of the four discussed above requires that highresolution meter data leave the home. Options $c$ and $d$ can both accommodate highly dynamic pricing, but greatly alleviate privacy concerns.

\subsubsection{Wholesale settlement}

Settlement is the term used to describe the process of accounting and arranging payments for the electricity bought by suppliers from Generators within the wholesale electricity market. It is important that demand response is accurately accounted for within this process, in order that suppliers are rewarded for the demand response actions of their consumers.

An obvious way of achieving this would be to use half-hourly data from every consumer. Indeed, Elexon, the entity responsible for performing settlement in the wholesale electricity market in the UK, has indicated that the use of smart meter data to improve the settlement process constitutes an important potential benefit and driver for the collection of data at half-hourly resolution (Elexon, 2011). 
In the past, half-hourly metering of every consumer was prohibitively expensive, and so settlement for domestic and other small consumers is conventionally performed using a process termed 'profiling'. This relies on half-hourly metering a small but statistically representative sample of the population and using this data to create a 'deemed profile' (Elexon, 1997). The rest of the population are then assumed to have similar profiles. Any differences between a consumer's actual profile and the deemed profile, including those related to demand response, are effectively ignored, and thus suppliers cannot benefit from the demand response actions of individual consumers.

However, the demand response actions of groups of consumers can be accommodated through the use of alternate profiles. In the UK, two profile classes are used for domestic consumers, corresponding to the two common electricity tariffs - standard flat-rate and Economy 7 . The Economy 7 profile class allows settlement to account for demand response based on a static time-of-use tariff, as well as demand response based on the automated load control (switching of electric storage heaters). 
This concept can be extended to include more innovative types of tariff. Indeed, Elexon has stated that 'there is no fundamental obstacle to using profiling to support dynamic tariffs in the GB market' (Elexon, 2008), such as the six-rate critical peak EdF Tempo tariff (IEA, 2008) used in France. Furthermore, profiling arrangements could potentially support tariffs with even more flexibility, for example where register switching times are flexible (as per Figure $3 \mathrm{~d}$ ), or called at short notice, for example in response to changes in frequency (Elexon, 2008). Where the profile classes are adequately representative of the various consumer segments, profiling therefore has the scope to account for demand response. From a privacy perspective, profiling has merit because it does not require load profile data from the entire population, only from a statistically representative sample.

Profiling however might be inadequate under certain circumstances. A small, niche supplier for example, might have customers whose load profiles are quite different from those of the profile classes. Under these circumstances, the use of half-hourly demand data from the supplier's consumers would provide a more accurate settlement process. Where consent has been obtained from the consumer, the use of their half-hourly demand data within the settlement process should therefore be allowed. 


\subsubsection{Fast demand response}

It is anticipated that demand response will be increasingly used as a fast response resource for system balancing and this service will need to be effectively metered. Firstly, the System Operator will wish to verify in realtime that any mechanism called to provide demand response has done so as expected. Secondly, there is the matter of improving predictions of the expected response and availability for future use.

For the real-time monitoring of fast response the System Operator is likely to focus on the conventionally metered demands at large substations, as described earlier in section 4.1, and again it is unlikely that interval data from individual household smart meters will have any role in this. There is however the possibility that the operator would wish to see some acknowledgement of operation coming from the appliances that are providing the demand response. As an example, the LIPAedge demand response system in Long Island, New York, provides a fast reserve service by automatically controlling consumer's air conditioning units using programmable thermostats (Kirby, 2003). A two-way pager system is used to both control the thermostats, and to receive response and monitoring information from them. In this example, the communication with the appliance is not via the smart meter although it could well be routed that way in future schemes. The point however is that (half-hourly) interval data for the whole house consumption is unlikely to be relevant for the purposes of fast demand response. 


\subsection{Distribution system operation and planning}

The distribution system refers to the medium and low voltage networks that feed power from large transmission system substations (grid supply points) down to the consumers. In the UK, the distribution system includes the $132 \mathrm{kV}, 33 \mathrm{kV}, 11 \mathrm{kV}$ and $400 \mathrm{~V}$ networks (Central Networks, 2006). The higher levels are monitored at the large substations (bulk supply points, and primary substations), and so for reasons discussed previously, there is no obvious role for smart meter data at these levels. Network operators however have little visibility of the lower levels of the network (11kV and 400V), and as a result it is here that smart meter data could prove to be most useful.

\subsubsection{Voltage and power quality}

Smart meters can readily be designed to measure voltage, in addition to energy consumption, which has been the principal concern of this paper. The voltage data could include steady-state voltages, flicker and harmonics all of which are of considerable interest to network operators, who have a duty to maintain voltages and power quality within strict limits throughout their networks. The information could also allow rapid identification of fault locations and in the longer term it could be used for historical performance monitoring of quality of service by the network operator or regulator.

There are no reported concerns regarding the use of voltage data from smart meters, and there is no obvious way in which such data could be used to infer private, in-home activities. It would seem reasonable therefore that the processing of such data should not be subject to the same restrictions as demand data. 


\subsubsection{Outage detection and fault location}

Detection of faults on the low-voltage network has traditionally relied upon customers calling up to report an outage. As such calls start to build up, they can be used to piece together a picture of the extent of the outage and likely location of the fault. The high geographic resolution of smart meters however could provide this information almost instantaneously, thereby minimising 'customer minutes lost' - an important parameter by which network operators are judged and sometimes penalised. To achieve this, outages could be recognised from energy consumption data or, equally well, from the nonsensitive voltage data described above.

\subsubsection{Operation nearer to limits}

The distribution system must be operated within the limits of the network infrastructure. In order not to cause equipment failure or to reduce equipment lifetime, current flow through power cables and transformers should not cause the thermal capacity of the equipment to be exceeded. Furthermore, there is a regulatory requirement that network voltages seen by consumers are maintained within limits of the network's nominal voltage - in the UK this is currently $230 \mathrm{~V}+10 \%-6 \%$ (Electricity Regulations, 2002). The absence of real-time measurements from the low-voltage network however, can mean that operators have to be quite cautious and leave generous margins in operating the network. Smart meter data could be used to operate networks nearer to their limits, potentially delaying expensive network reinforcements, or reducing the number and duration of customer outages. 
It should be possible to make use of anonymous or non-sensitive data for many of the activities associated with this application. As discussed previously, voltage data should have no privacy impacts and so could be used for monitoring network voltages. Monitoring that is associated with transformers could be achieved by installing metering at the secondary substations (though at additional cost), or alternatively by employing data scrambling techniques. For example, an algorithm could be used such that the data from each smart meter is meaningless, but that the aggregated sum is meaningful (Shi et al., 2011), and which could therefore be used for monitoring current flows through substation transformers. For network power flows, there is the possibility of using (non-sensitive) subsets of demand data where relevant - for example, peak demand data alone should be sufficient for determining the peak loading on cables.

Ultimately however, there is an argument that individual household data would give the network operator the clearest picture about power flows particularly for very localised parts of the network. Furthermore, it is envisaged that this will become increasingly valuable, given the expected uptake of low-carbon technologies such as electric vehicles and heat pumps (Strbac et al., 2010). 
The above discussion refers to the Distribution Network Operator, in their performance of a 'regulated duty'. Furthermore, this application is clearly in the best interests of the consumers, in terms of ensuring a continuous, highquality electricity supply. This application would therefore appear to have a strong case for the use of smart meter data. Nonetheless, there may well be ways of achieving improved optimisation of network assets whilst maintaining privacy, for example through appropriate data selection or processing techniques. Further research is recommended on this topic.

\subsubsection{Planning reinforcement}

Distribution networks are designed to meet the expected demands of consumers, whilst ensuring that the thermal operating limits of power cables and transformers are not exceeded, and voltages seen by consumers stay within mandatory limits. The general design approach for residential distribution networks has changed little over the past decades (P B Power, 2003).

For domestic consumers in the UK, network design is generally based on the presence or not of electric heating within the dwelling (Central Networks, 2006). The parameter of importance is the after diversity maximum demand (ADMD), which formally refers to 'the maximum demand, per customer, as the number of customers approaches infinity' (McQueen et al., 2004). This term refers to the supply capacity required per customer, and is used in network engineering calculations, for example, in order to estimate the maximum expected voltage drop along cables. As an example, a dwelling without electric heating would typically be assigned an ADMD of $2 \mathrm{~kW}$ in the UK (Central Networks, 2006). 
The advent of low-carbon technologies however poses a challenge to this traditional approach to distribution network design. Wide-scale use of electric vehicles and heat pumps for example, may increase demand considerably (Strbac et al., 2010), and will likely change the nature of the ADMD. Furthermore, microgeneration technologies, such as photovoltaic arrays, are of concern due to their potential to cause voltage rise along cables (Thomson and Infield, 2007).

Faced with such challenges, data from smart meters could assist network operators in making well-informed decisions regarding future network design or reinforcement. Rather than using assumed demand data, actual demand data could be used. Similar to the previous section's discussion, there is an argument that data from each and every consumer would give network operators the fullest picture on which to base their design decisions. Furthermore, this application would also appear to have a strong case for the use of smart meter data, as it is a 'regulated duty', and is in the best interests of the consumer.

Alternatively, it may be the presence of low-carbon technologies that is of most relevance to network design, rather than the measured demand data from each individual household. The presence of microgeneration, heat pumps and vehicle charging points, could be identified and accounted for in the same way that electric storage heating is in current design practice. This would align the network capacity to the equipment permanently installed in dwellings, rather than to the consumption habits of the current residents. It would also avoid the need of individual demand data and thus help maintain consumer privacy. 
It is noted that certain low-carbon technologies, electric vehicles and heat pumps in particular, can have a significantly different impact on the network depending on whether they are controlled in a co-ordinated 'smart' way. Strbac et al. have estimated that the benefits to the UK of deferred network reinforcement costs associated with 'smart meter-enabled active control' of electric vehicles and heat pumps (under a 100\% penetration scenario) could be in the order of £3-10bn (Strbac, 2008). It may be important therefore, in future network design, to be able to identify when dwellings have an 'active' or 'passive' controlled low-carbon technology. It is not obvious however, that individual demand data would be relevant for this classification. An extension of the dwelling classification process described above would appear to be adequate. It is noted, for example, that many electric storage heaters in the UK are 'actively controlled' via the Radio Teleswitch system (McCartney, 1993), and that the usefulness and operation of this system is not dependent or reliant upon the communication of high-resolution demand data to outside the home.

\section{Conclusions}

Consumer privacy concerns have the potential to delay smart meter deployments if they are not appropriately addressed at an early stage. 
Examination of the types of concerns that have been documented reveals an important distinction between the privacy of the home from the outside world 'external privacy', and the privacy of individual members of the household from each other 'internal privacy'. Information feedback enabled by smart metering systems is likely to have important implications for the internal privacy of the home, and could affect household dynamics in unexpected, and potentially undesirable, ways.

Concerns are based on the potential for activities normally thought to be private to be inferred from smart meter data. Data resolution however determines the type of information that is disclosed. Current resolutions of smart metering systems (15 minute to 1 hour) provide a strong indication of occupancy, but have much less potential to reveal individual appliance use. Concerns should be rationalised accordingly.

This paper has revealed that the requirements for sensitive meter data within the electricity supply industry are perhaps not as great as might be expected. The use of personal data within legitimate industry applications can often be minimised or avoided, and appropriate data selection or processing techniques have been suggested for consideration. 
Of the legitimate applications investigated, distribution system operation and planning would appear to have the strongest case for the use of smart meter data from every individual household, in particular to optimise the operation of network assets given increasing penetrations of low-carbon technologies such as electric vehicles. It is suggested however that much can be done to maintain privacy within this application, for example by improving the current structural classification of dwellings within network design, and this is recommended as a useful topic for further research.

Another valid case for the use of half-hourly smart meter data would appear to be within wholesale settlement. Firstly, such data could be used to increase the number and types profile classes used in current profiling arrangements, for example to allow demand response to be adequately accounted for. Secondly, where consumer load profiles are consistently different from the settlement profile classes, as may be the case for small, niche suppliers, such data could be used to improve the accuracy of the settlement process.

This paper suggests that the use of appropriate 'privacy friendly' techniques can considerably reduce the electricity supply industry's requirements for sensitive smart meter data. It is recommended that such methods are considered as part of the ongoing development of smart meter architecture. 


\section{Acknowledgements}

This work was supported by Secure Meters (UK) Ltd. and by the Engineering and Physical Sciences Research Council, UK, within the HiDEF Supergen project (EP/G031681/1) and the Transition Pathways to a Low Carbon Economy project (EP/F022832/1).

\section{References}

Albadi, M.H., El-Saadany, E.F., 2008, A summary of demand response in electricity markets. Electric Power Systems Research, 78, 1989-1996.

AlertMe. 2011, AlertMe - Energy bill reduction and home security monitoring. http://www.alertme.com/.

Allcott,H. , 2010. Social Norms and Energy Conservation. Available from: http://web.mit.edu/allcott/www/.

Allcott, H., Mullainathan, S., 2010, Behavior and Energy Policy. Science, 327, 1204-1205.

Anderson, R., Fuloria, S., 2010. On the security economics of electricity metering, In: The Ninth Workshop on the Economics of Information Security (WEIS 2010), Anonymous Harvard University, USA, June 7 - 8,.

Bohli, J., Sorge, C., Ugus, O., 2010. A Privacy Model for Smart Metering, In: Communications Workshops (ICC), 2010 IEEE International Conference on, Anonymous IEEE Conferences, pp. 1-5.

Cavoukian, A., Polonetsky, J., Wolf, C., 2010, SmartPrivacy for the Smart Grid: embedding privacy into the design of electricity conservation. Identity in the Information Society.

CEC, 2009., Directive 2009/72/EC of the European Parliament and of the Council of 13 July 2009 concerning common rules for the internal market in electricity and repealing Directive 2003/54/EC. Available from: http://eurlex.europa.eu/LexUriServ/LexUriServ.do?uri=OJ:L:2009:211:0055:0093:EN:PDF.

CEC, 1995., Directive 95/46/EC of the European Parliament and of the Council of 24 October 1995 on the protection of individuals with regard to the processing of personal data and on the free movement of such data. Available from: http://eurlex.europa.eu/LexUriServ/LexUriServ.do?uri=CELEX:31995L0046:en:HTML.

Central Networks, 2006., Network Design Manual. Available from: http://www.eonuk.com/downloads/Network Design Manual.pdf.

Council of Europe, 1950, Convention for the Protection of Human Rights and Fundamental Freedoms., I-III.http://conventions.coe.int/treaty/en/Treaties/Html/005.htm. 
Darby, S., 2000. Making it obvious: designing feedback into energy consumption, Naples, Italy ed. In: Proceedings of the 2nd International Conference on Energy Efficiency in Household Appliances and Lighting. Anonymous Italian Association of Energy Economists / EC-SAVE programme, 26-28 Sept 2000,.

Darby, S., 2006., The effectiveness of feedback on energy consumption: A review for DEFRA of the literature on metering, billing and direct displays. Available from: http://www.eci.ox.ac.uk/people/darbysarah.php.

Department for Energy and Climate Change, 2010., 2050 Pathways Analysis. Available from: http://www.decc.gov.uk/en/content/cms/tackling/2050/2050.aspx.

Depuru, S.S.S.R., Wang, L., Devabhaktuni, V., 2011, Electricity theft: Overview, issues, prevention and a smart meter based approach to control theft. Energy Policy, 39, 10071015.

Drenker, S., Kader, A., 1999, Nonintrusive monitoring of electrical loads. IEEE Computer Applications in Power, 12, 47-51.

Electricity Regulations, 2002, The Electricity Safety, Quality and Continuity Regulations 2002. Crown Copyright 2002, Statutory Instruments, No. 2665.

Elexon, 2011., Smarter settlement - making the most of tariff innovation. Available from: http://www.elexon.co.uk/ELEXON\%20Documents/Smarter Settlement Final.pdf.

Elexon, 2008., Limitations of the current settlement arrangements for dynamic tariffs. Available from: http://www.elexon.co.uk/ELEXON\%20Event\%20Documents/svg92 09.pdf.

Elexon, 1997., Load profiles and their use in electricity settlement. Available from: http://data.ukedc.rl.ac.uk/browse/edc/Electricity/LoadProfile/doc/Load Profiles.pdf.

Engage Consulting, 2010., Smart Metering Security \& Privacy Control Points. Prepared for the Energy Networks Association. Available from: http://www.energynetworks.org/ena energyfutures/ENACR009 002 1.1-

Control\%20Points.pdf.

FoeBuD e.V. 2008, Technology: Yello Strom GmbH - BigBrotherAwards . http://www.bigbrotherawards.de/2008-en/.tec.

Hargreaves, T., Nye, M., Burgess, J., 2010, Making energy visible: A qualitative field study of how householders interact with feedback from smart energy monitors. Energy Policy, 38, 6111-6119.

Hildebrand, 2011, DEHEMS Cycle 2 participant demand data., Database file.

IDC Energy Insights. 2011, New Study Projects 74.6 Million Smart Meters Will be Shipped Worldwide Annually by 2015. http://www.idc.com/about/viewpressrelease.jsp?containerld=prUS22730711\&sectionld=null \&elementld=null\&pageType=SYNOPSIS.

IEA, 2008., Worldwide Survey of Network-driven Demand-side Management Projects.

Jamieson, A., 2009, Smart meters could be 'spy in the home'. The Telegraph, Energy.

Kirby, B.J., 2003., Spinning reserve provided from Responsive Loads. Available from: http://www.ornl.gov/ webworks/cppr/y2001/rpt/116213.pdf. 
Knyrim, R., Trieb, G., 2011, Smart metering under EU data protection law. International Data Privacy Law, 1, 121-128.

Lerner, J.I., Mulligan, D.K., 2008, Taking the "Long View" on the Fourth Amendment: Stored Records and the Sanctity of the Home. Stanford Technology Law Review, 3.

Lisovich, M.A., Mulligan, D.K., Wicker, S.B., 2010, Inferring Personal Information from Demand-Response Systems. Security \& Privacy, IEEE, 8, 11-- 20.

McCartney, A.I., 1993, Load management using radio teleswitches within NIE. Power Engineering Journal, 7, 163-169.

McDaniel, P., 2009, Security and Privacy Challenges in the Smart Grid. Security \& Privacy, IEEE, 7, 75-77.

McKenna, E., Ghosh, K., Thomson, M., 2011. Demand response in low-carbon power systems: A review of residential electrical demand response projects, In: 2nd International Conference on Microgeneration and Related Technologies, Anonymous University of Strathclyde, Glasgow, UK, 4-6 April 2011,.

McQueen, D.H.O., Hyland, P.R., Watson, S.J., 2004, Monte Carlo simulation of residential electricity demand for forecasting maximum demand on distribution networks. IEEE Transactions on Power Systems, 19, 1685-1689.

Mott MacDonald, 2007., Appraisal of Costs \& Benefits of Smart Meter Roll Out Options. Available from: http://webarchive.nationalarchives.gov.uk/+/http://www.berr.gov.uk/files/file45997.pdf.

Ofgem, DECC, 2011., Smart Metering - Response to Prospectus Consultation. Available from: $\quad$ http://www.ofgem.gov.uk/Pages/Morelnformation. aspx?docid=56\&refer=eserve/sm/Documentation.

Owen, G., Ward, J., 2006., Smart Meters: Commercial, Policy and Regulatory Drivers.

P B Power, 2003., Micro generation network connection.

Quinn, E.L., 2009, Privacy and the New Energy Infrastructure. Social Science Research Network, Working Paper Series, 11th July 2011.

Rogai, S., 2006, ENEL's Metering System and Telegestore Project. NARUC Conference.

Shi, E., Chan, T., Rieffel, E., Chow, R., Song, D., 2011, Privacy-Preserving Aggregation of Time-Series Data. Proceedings of NDSS, 17.

Strbac, G., Gan, C.K., Aunedi, M., Stanojevic, V., Djapic, P., Dejvises, J., et al., 2010., Benefits of Advanced Smart Metering for Demand Response based Control of Distribution Networks.

Strbac, G., 2008, Demand side management: Benefits and challenges. Energy Policy, 36, 4419-4426.

Subrahmanyam, P.A., 2005., Network Security Architecture for Demand Response/Sensor Networks. 
Swan, L.G., Ugursal, V.I., 2009, Modeling of end-use energy consumption in the residential sector: A review of modeling techniques. Renewable and Sustainable Energy Reviews, 13, 1819-1835.

Thomson, M., Infield, D.G., 2007, Network Power-Flow Analysis for a High Penetration of Distributed Generation. IEEE Transactions on Power Systems, 22, 1157-1162.

TILT. 2009, Dutch Senate rejects Smart Metering Bill. http://www.tilburguniversity.edu/research/institutes-and-researchgroups/tilt/news/archive/2009/04/. 